\title{
El ser humano como arma: Los ataques suicidas
}

Gema Sánchez Medero*

\subsection{Introducción}

Los atentados del 11-S vinieron a reafirmar tanto la eficacia como la eficiencia de los atentados suicidas como instrumento de terror, como la letalidad de la combinación avión-piloto suicida que ya demostraron los kamikaze japoneses (Calvo, 2008, p. 17). A partir de entonces, este tipo de acciones no ha hecho más que incrementarse, dado su efectividad. Así, entre 1980 a 2003, se registraron 315 ataques de este índole, mientras que tan solo entre 2004 y 2005 se efectuaron 489 (Hassan, 2008). De tal manera, que hasta este momento se han producido atentados suicidas, en más de 34 países, y 42 han sufrido atentados contra sus intereses en el extranjero. Por tanto, los atentados terroristas se han convertido en un método de guerra contra el ocupante israelí, y luego contra la ONU, en el Líbano en 1982, en Sri Lanka en 1987, en Palestina en 1994, en Turquía en 1995, en Cachemira en 1998, en Chechenia en 2000, en Rusia

\footnotetext{
* Profesora de Ciencias Políticas y de la Adminstración de la Universidad Complutense de Madrid.
} 
en 2002 y en Irak en 2003. Después se ha vuelto una técnica terrorista indirecta contra EE.UU. en Kenya y Tanzania en 2001, contra Francia en Pakistán, contra Australia en Indonesia en 2002, entre otras. Además, conforma un procedimiento de guerra civil o religiosa en Arabia Saudita y en Pakistán, y desde 2003 en Irak. Y, actualmente, se han internacionalizado, gracias al atentado contra el World Trade Centre, donde murieron 3053 víctimas. Por tanto, viendo estos datos, no cabe duda de que los atentados suicidas son una de las amenazas a las que tendrá que enfrentarse el siglo XXI, ya que la combinación de terrorismo suicida y armas de destrucción masiva constituyen un coctel letal.

\subsection{El terrorismo "suicida"}

Existen múltiples definiciones sobre el terrorismo suicida. Así, por ejemplo, el Director del Instituto de Política Internacional sobre Contra Terrorismo (ICT) señala que el terrorismo se puede definir como "el método operativo en el cual el acto mismo del ataque depende de la muerte del perpetrador" (Ganor, 2002), es decir, es una situación en la que el terrorista es plenamente consciente de que si no se mata, el ataque planeado no se llevará a cabo. La muerte es una condición necesaria para garantizar la eficacia del atentado, y en el que el propio terrorista decide deliberadamente poner fin a su vida como parte del plan, descartándose en consecuencia aquellos casos en los que es engañado y el explosivo que transporta es detonado a control remoto por los organizadores (Merlos, 2008, p. 60). De ahí, que únicamente los terroristas puedan salvar la vida: a) por problemas técnicos de la operación, b) por ser víctimas de medidas preventivas de las fuerzas de seguridad del Estado-blanco o, c) por su propio arrepentimiento y marcha atrás en la fase inmediatamente anterior al estallido de la carga. Por tanto, esta táctica nos recuerda que hay personas que consideran que su lucha - sea cual sea su causa- es más importante que sus propias vidas (Beriain, 2007, p. 117).

Por otra parte, hay que tener en consideración que además de no existir una unidad definitoria del concepto de "terrorismo suicida", se suelen usar indistintamente los términos de "suicida", "mártires" y "kamikazes". El término suicidio es el acto por el que el individuo, deliberadamente, se provoca la muerte a sí mismo. El término kamikaze (viento 
divino) de origen japonés, fue utilizado originalmente por los traductores estadounidenses para referirse a los ataques suicidas efectuados por los pilotos de una unidad especial perteneciente a la Armada Imperial Japonesa contra las embarcaciones de la flota de los aliados. Aunque en Japón no se utiliza con este sentido, sino más bien se prefiere el término Shinpu tokubetsu kogeki tai (Unidad Especial de Ataque Shinpu). Hoy en día son considerados como ciudadanos que defendían su tierra, su historia, su patriotismo, su idealismo y sus códigos morales (Fernández de los Ríos, 2007, p. 118).

El término mártir proviene de la palabra latina "martor", el término martirio hace referencia a la persona que padece o muere por defender sus creencias y convicciones y por difundirlas. En la tradición cristiana el mártir es una persona que moría por su fe religiosa, y en muchos casos era torturado hasta la muerte. Los mártires son víctimas que saben que van a morir y eligen hacerlo dando a su muerte la significación del testimonio de que hay verdades que no pueden ser borradas ni olvidadas (Beriain, 2007, p. 110). El mismo Jesucristo es considerado por los cristianos como el primer mártir, aquel que dio testimonio de su fe ante Poncio Pilatos y pagó con su vida por este gesto. En el Islam, la palabra para designar mártir es "shahid" y "shahada" significa martirio, en un principio estaba designada al testimonio, pero no a la muerte sagrada. Solo después de la conquista musulmana de Palestina, en el siglo VII, la noción de testimonio acabó significando la muerte sagrada para el Islam. Y en el judaísmo la palabra para designar martirio es "qiddush ha-shem", que significa "en el nombre de Dios". En dicha religión la inspiración para las prácticas de los celotes y sicarios, proviene de la hazaña de Fineas, que fue sumo sacerdote después de Aaron, durante el período fundacional en el Sinaí. Por iniciativa propia, Fineas mató a un líder tribal y a su concubina extranjera, porque violaban un lugar sagrado. Este acto le ganó el favor divino, y se convirtió en el fundamento judío para matar sin juicio, pero, solo en tres situaciones: en caso de ser obligado a cometer idolatría (avodah zarah); en caso de incesto (gilui arayot); y en caso de homicidio (shfichut damin). El primer caso de martirio relatado en la Torah fue el sacrificio no consumado de Isaac hijo de Abraham solicitado por Dios al propio Abraham para probar su fe. 
Por tanto, ¿cómo interpretar la conducta de mártires, kamikazes y terroristas suicidas? Los tres presentan por lo menos las siguientes características comunes: a) sus acciones son el resultado de una clausura mental (Kruglanski, 2004); b) llegan a ser considerados por las generaciones posteriores como personas que realizaron actos altruistas (Fernández de los Ríos, 2007, p. 117); y, por último, c) la emisión de tales conductas no se pueden explicar exclusivamente ni por patología personal, ni por pobreza, ni por procesos sociales de opresión, humillación y exclusión social, ni por mecanismos psicológicos de desesperación, ni por una elección racional libre y equilibrada (Caplan, 2006; Ferrero, 2006; Pyszczynski, Solomon y Greenberg, 2003). En todos los casos, las misiones suicidas y los procesos de martirio tienen un sentido, unas razones y unas causas difusas (Gambetta, 2005). Los mártires, los kamikazes y los terroristas suicidas juegan con una razón inapelable: la propia vida es un arma (Bloom, 2005a; Reuter, 2002). Un arma que en el cristianismo y el judaísmo sirve para defender la fe, mientras que para el islamismo, además, se utiliza para proteger a la nación contra los enemigos que invaden su territorio. Aunque el islamismo rechaza la etiqueta de suicidio para este tipo de acciones, optan mejor por el término de martirio, ya que sus ideólogos entienden que la primera es fruto de la debilidad espiritual y religiosa de un musulmán, mientras que la segunda es la máxima expresión de su sacrificio y su convicción verdadera (Merlos, 2008, p. 64). Por tanto, en las tres religiones el término mártir está estrechamente vinculado con la defensa de la fe.

Aunque en las tres religiones monoteístas (judaísmo, cristianismo e islamismo) el suicidio religioso o martirio está prohibido en las tres. En las religiones abrahámicas, el suicido está íntimamente vinculado al pecado, porque Dios niega al individuo el derecho a dar fin a su propia identidad terrenal. El poder sobre la vida y la muerte no lo detenta legítimamente el hombre, sino el Dios único, creador y destructor, y sus delegados terrenales (Asad, 2008, p. 85). En el Islam el suicidio está prohibido porque solamente Dios es capaz de dar y quitar la vida. El Corán prohíbe el suicidio (4:29) y el Profeta ha declarado en varias ocasiones que el suicidio es ilícito en el Islam. Por eso, después de la muerte, un ángel aparece e interroga al muerto sobre los pecados cometidos para decidir si la persona va al paraíso o al infierno. Pero aquellos que se suicidan en atentados terroristas no mueren como mártires sino como 
suicidas y son condenados por la ley islámica. Así, en el verso 190 del capítulo 2 del Corán se nos advierte: "enfrentaos por Alá a quienes se enfrenten contra vosotros, pero no os excedáis. Alá no ama a los que se exceden" (Andelsman, Szechtman y Toker, 2010, p. 27). También está prohibido todos los crímenes en contra de los otros seres humanos, el Corán establece que "quien mata a una sola persona es como si fuera matado a toda la humanidad, y, consecuentemente, salvar a un ser humano equivale a haber salvado a toda la humanidad" (Corán, 5:32). El Corán está lleno de versículos que hacen referencia a los cinco valores principales que hay que proteger, conocidos como los Zaruriyat al-famsa, que son: la vida, la religión, la descendencia, la mente y la propiedad. Por lo tanto, la vida humana no ha de ser violada, el honor no puede ser mancillado y la propiedad no puede ser confiscada.

No obstante, la libre interpretación de los textos sagrados islámicos permite que algunas corrientes minoritarias encuentren en ellos un sentido más radical y favorable a sus intereses. Los textos religiosos, por su flexibilidad, se prestan a necesidades ideológicas de cualquier tendencia que hace su propia versión para llevar el agua a su molino (Saleh, 2007, p. 167). Así, para justificar religiosamente la violencia, los ideólogos y los militantes del terrorismo islamista se sirven del concepto islámico de yihad, aunque literalmente no signifique guerra santa (el término guerra es designado en el Corán con las palabras hard y qitad), en la práctica puede ser equiparado con él (Jordán, 2004, p. 38). Y claro, el Corán está lleno de pasajes en los que, sin utilizar el término yihad, se habla explícitamente de combatir a los infieles y a los apóstatas, incluso algunos autores se han servido de su interpretación para justificar la violencia.

Por ejemplo, Sayid Qutb (uno de los teóricos más citados por los yihadistas): “QQue quienes cambian la vida de acá por la otra combatan por Dios! A quien, combatiendo por Dios, sea muerto él salga victorioso, le haremos una magnífica recompensa (Corán, 8:39). Combatid contra ellos (los infieles) basta que dejen de induciros a apostatar y se rinda todo culto a Dios. Si cesan, Dios ve bien lo que hacen (Corán, 9:29). Combatid contra quienes, habiendo recibido la Escritura [los cristianos y los judíos] no creen en Dios ni en el último día, no prohíben lo que Dios y su enviado han prohibido, ni practican la religión verdadera, hasta que humillados, paguen el tributo directamente” (Jordán, 2004, p. 46). 
Asimismo, Alá ordenó a los musulmanes que lucharan diciendo: "Se os ha prescrito que combatáis, aunque os disguste. Puede que os disguste algo que os conviene y améis algo que ni os conviene. Ala sabe mientras que vosotros no sabéis" (Guidère y Morgan, 2007, p. 135).

Por lo tanto, la lucha no es terrorismo sino guerra, y para librarla adoptan un enfoque estratégico asimétrico, porque es el único que les permite derrotar a un adversario más poderoso, y los ataques suicidas están dentro de esta. El problema es que por eso muchas matanzas han sido cometidas con pretextos religiosos, muchos derechos han sido pisoteados y muchos poderes usurpadores (Saleh Alkhalifa, 2007, p. 168).

\subsection{Los ataques "suicidas"}

Se puede hablar de la existencia de atentados "suicidas" desde el primer siglo de nuestra era, cuando los judíos zelotes y sicarios lucharon contra el dominio del Imperio Romano. Sus elementos más violentamente activos, denominados sicarii (literalmente, el hombre violento), no dudaban en suicidarse para lograr sus fines o evitar caer en manos enemigas (Baños, 2008, p. 4). Estos grupos, decididos a liberar Judea de la ocupación romana, emplearon la violencia para provocar una sublevación popular, que precipitó, según los historiadores, la "guerra judía" del año 66 d.C., en la que se produjeron numerosos asesinatos públicos y otros actos de violencia en Judea desde el año 4 a.C. hasta el 70 d.C., aproximadamente (Pape, 2006, p. 25). Los grupos musulmanes como Ismaelitas o Hashashiyun en los siglos XI y XII, secta seguidora de una corriente chiíta que surgió de la disputa por la sucesión de Jafar al-Sadiq, quien reconoció a los chiitas como el sexto imán, o sucesor espiritual de Mahoma. Los ismaelitas son conocidos porque aceptan solo a 7 imanes, en vez de los 12 que son reconocidos por los otros chítas. La leyenda les consideraba guerreros suicidas, fedayines dispuestos a morir por el Islam que actuaban tras una formación en la que se incluían rituales en los que el hachís estaba presente, lo que influía en la modificación del comportamiento de los guerreros que llegaban a adquirir un total desprecio por la vida. Por otra parte, los asesinos israelíes, una secta musulmana chií asentada en el noroeste de Irán en los siglos XI y XII, creó una organización eficaz para el uso de planificación, sistemático y 
duradero del asesinato político por medio de misiones suicidas (Pape, 2006, p. 27). Durante dos siglos, las dagas de los asesinos aterrorizaron y desmoralizaron a los dirigentes, principalmente sunníes, de la región, así como a los líderes de los Estados cristianos de las cruzadas, pues llevaron a cabo más de cincuenta asesinatos dramáticos e inspiraron un nueva palabra "asesinato" (Pape, 2006, p. 27). De hecho, el terrorismo hasta la Primera Guerra Mundial era en gran medida suicida, puesto que rara vez el ejecutante lograba escapar con vida (Witker, 2005, p. 238).

Otro hito histórico es el popular caso de los kamikazes japoneses. Estos pilotos eran especialmente adiestrados para destruir barcos enemigos en acciones suicidas (Baños, 2008, p. 4). Las acciones más numerosas fueron los ataques con aeroplanos, empleándose desde la batalla del Golfo de Leite hasta el final de la Segunda Guerra Mundial. La Oka ("flor de cerezo") era una bomba pilotada y propulsada por cohete, que una vez que era desprendida del avión escolta, el piloto volaba planeando bajo hasta identificar un blanco, y entonces ascendía y atacaba en picada precipitándose $50^{\circ}$ y encendía los cohetes (Gambetta, 2005, p. 25). Esto le daba una velocidad de ataque de 648 kilómetros hora, lo que hacía que fuera muy difícil de derribar (Gambetta, 2005, p. 25). Pero está táctica requería que los pilotos mantuvieran los ojos abiertos hasta el momento de dar en el blanco, ya que muchos pasaban de largo. Además, debían armar sus bombas en cuanto habían identificado sus blancos, ya que muchos olvidaban este aspecto provocando el fracaso de la operación. Asimismo, los ataques suicidas tenían prioridades. Si se trataba de un portaviones, el mejor blanco era el elevador principal; si era otro tipo de gran embarcación de guerra el objetivo debía ser la base del puente de mando; y si eran destructores y pequeños buques, el mejor impacto era entre el puente de mando y el centro del navío. Así, el método requería una habilidad muy particular por parte del piloto, puesto que el impacto debía producirse en la cubierta del navío elegido, además era de gran importancia que el piloto supiera pilotar entre el fuego enemigo. De ahí, que fueran sometidos a entrenamientos muy rigurosos, aunque sus acciones fueron menos exitosas de lo que en un principio se esperaban. 
Figura 1. Kamikazes japoneses

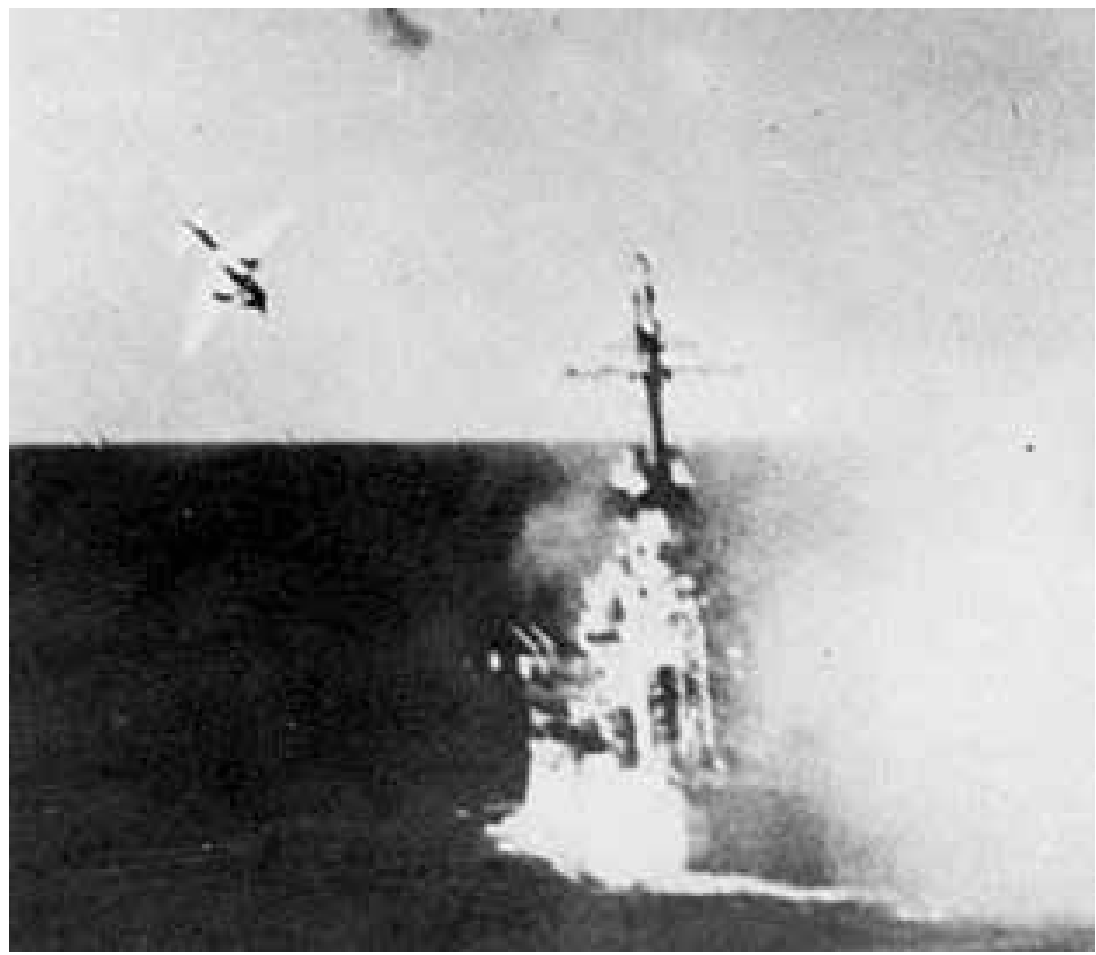

Otra de las acciones que llevan a cabo estos kamikazes japoneses eran los ataques con submarinos suicida. A principios de 1943, dos oficiales navales de baja graduación fabricaron unos torpedos tripulados, y solicitaron al Estado Mayor Naval que se emplearan estos artefactos en combate (Gambetta, 2005, p. 27). Los torpedos kaiten ("cielo cambiante") eran básicamente dos torpedos de "lanceta larga" estándar, unidos y provistos de una torreta blindada de mando y un periscopio ( $\mathrm{O}^{\prime} \mathrm{Neill}$, 1981, p. 226). Las minas de hombre rana era otra acción kamikaze. La táctica era lanzar, desde pequeños botes cercanos a los lugares de desembarco enemigo, hombres equipados con aparatos para respirar y minas atadas a un extremo del poste, caminarían por el lecho marítimo hasta sus blancos y allí harían detonar las minas contra los cascos de las lanchas de desembarco (Gambetta, 2005, p. 28). Pero en general, con excepción de los ataques aéreos suicidas, estas armas no resultaron muy efectivas. Además, el sistema era muy costoso y a medida que avanzaba la guerra era preciso ahorrar aviones. 
Los pilotos, habitualmente, eran jóvenes de entre 25 a 35 años que procedían de algunas de las fuerzas aéreas japonesas, pero cuando los efectivos empezaron a escasear se tiró de las escuelas de cadetes. Normalmente eran voluntarios que estaban dispuestos a dar la vida por su país, aunque otros eran leales religiosos shintoístas que seguían el código de honor bushido de los samuráis, y otros, simplemente eran simpatizantes de movimientos de extrema derecha o sentían un amor exacerbado por el emperador y su familia. Sin embargo, se podría decir que el perfil que predominaba era ante todo, el sentido de la cultura japonesa del colectivo, en el que todos se sacrifican por el bien de la comunidad y de su familia. No obstante, es necesario señalar a este respecto, que según el debate entre expilotos kamikaze que se produjo en 1977 y que fue publicado por el famoso diario japonés Bungei Shunju, en muchos cuarteles nunca se solicitaron voluntarios para estas misiones.

La recompensa de estos jóvenes muertos en combate era formalmente venerados en Yasukuni Jinja con lo que se convertían en dioses nacionales (Gambetta, 2005, p. 47). La prensa y los escritores difundían su imagen sagrada y les atribuían hechos falsos y exagerados de sus hazañas Así, cuando un kamikaze moría, pasaba a ser un espíritu guardián del país y un héroe de la patria. De ahí, que antes de cada salida se llevara a cabo todo un ceremonial, en el que se entregaba al piloto la bandera del sol naciente, con inscripciones espirituales, una pistola o katana y una copa de sake o té antes de despegar, para envalentonarlos haciéndoles partícipes de esa figura casi mística que simbolizaban. Además, los pilotos componían un jisei no ku (poema compuesto cercano a la muerte), tradición que efectuaban los samuráis antes de cometer seppuku o harakiri, junto a este llevaban unas plegarias de sus familias y las condecoraciones que acaban de recibir.

Pero el primer ataque suicida, tal como hoy lo conocemos es el que se produce en el Líbano en 1981, después, está táctica se extenderá al resto del mundo. Así, la primera acción suicida en el contexto de violencia política moderna es ejecutada por Hezbollah en diciembre de 1981, y marca la consolidación de una variante del terrorismo revolucionario, especialmente letal, y como se afirma ut supra, estrechamente asociada a las demandas palestinas y al surgimiento de una identidad islámica reli- 
giosa con visos fundamentalistas (Witker, 2005, p. 238). En esa ocasión, los grupos terroristas pro-iraníes atacan la embajada iraquí en Beirut (Líbano), y marcan la consolidación de una variante del terrorismo revolucionario, especialmente letal, y como se afirma ut supra, estrechamente asociada a las demandas palestinas y al surgimiento de una identidad islámica religiosa con visos fundamentalistas (Witker, 2005, p. 238). Un año más tarde fue asesinado por este mismo procedimiento el presidente libanés, Bashir Gemayel. El 23 de octubre de 1983 se llevaron a cabo dos ataques simultáneos contra los cuarteles de marines de los Estados Unidos en Beirut y contra la fuerza francesa multinacional de paz en el Líbano. En total, 241 estadounidenses y 58 franceses murieron en el ataque que provocó la retirada de la fuerza multinacional del Líbano a finales de septiembre de 1984 (Gambetta, 2005, p. 120).

Hezbollah ("Partido de Dios") es una organización islamista libanesa prosiria y proiraní que cuenta con un brazo político y otro paramilitar. Fue fundada en Irán en 1979 y en el Líbano en 1982 como respuesta a la ocupación israelí de ese momento y fueron entrenados, organizados y fundados por un contingente de la guerra revolucionaria iraní. Hezbollah se constituyó como una fuerza aglutinante de varias organizaciones, grupos y movimientos radicalizados chítas. Bajo el auspicio del Ayatollah Khomeini, se le dio asistencia económica, material y entrenamiento militar. Además de su brazo armado, el movimiento cuenta con una infraestructura civil, que como Hamás, provee a la población de servicios sociales, sanitarios y educativos.

En su lucha, Hezbollah es una organización que emplea los ataques suicidas para presionar a las autoridades libanesas. Es más, es un arma esencial para la organización, hasta tal punto, que justifica su práctica en función de la necesidad de poner fin a la ocupación exterior de la patria chií. Así, en 1985, la "Carta Abierta" de Hezbollah declaraba lo siguiente: "Estados Unidos y sus aliados de la entidad sionista [...] han atacado nuestro país, han destruido nuestros pueblos, han masacrado a nuestros hijos, han profanado nuestros santuarios y han colocado sobre nuestras cabezas a esbirro criminales [...]" (Norton, 1987, p. 170). Además, también alegan que las operaciones suicidas están justificadas como el último recurso necesario por la inferioridad de la comunidad 
chií respecto a las armas convencionales de los ocupantes. Como explicó el Secretario General de Hezbolá:

Hablando de la experiencia [...] en el Líbano, para llevar a cabo una operación con un resultado de 8 o 9 soldados muertos, necesitaríamos entrenamiento, equipamiento, observaciones, el resultado sería de solo 3 o 4 muertes, debido a las resistentes fortificaciones del enemigo. En cambio, un único (mártir) sin entrenamiento o formación, conduciendo un autobús sin refuerzo militar ni grupos de apoyo, logró matar a 8 o 9 , y herir a unos 21, y atemorizar a toda la entidad israelí (Nasrallah, 2001).

Y también porque los enemigos son vulnerables a la presión coercitiva. En este sentido la "Carta Abierta" de Hezbolá declara lo siguiente: "Con la sangre de sus mártires y la lucha de sus héroes, la resistencia islámica ha sido capaz de vencer” (Pape, 2006, p. 229).

Posteriormente, dichas operaciones se extendieron a otros grupos como los Tigres Tamiles de Sri Lanka, también denominados "Tigres de Liberación del Eelam Tamil" (Liberation Tigers of Tamil Eelam). Este es el único grupo terrorista, a nivel mundial, que ha asesinado, mediante terroristas suicidas, a dos jefes de Estado (Rajiv Gandhi, mayo de 1991, y Primadaassa, mayo de 1993) (Witker, 2005, p. 245). Además, cometieron algunos atentados que resultaron ser especialmente sangrientos, como el del 31 de enero de 1996, cuando la explosión de un camión bomba en Colombo acabó con la vida de más de 200 civiles y provocó heridas a 1400. Y todo porque los Tigres Tamiles aplicaron y perfeccionaron el terrorismo suicida, no obstante, fueron los que inventaron el cinturón suicida y los primeros en emplear a mujeres en los ataques suicidas.

Aunque, realmente, los que realizaban acciones suicidas eran los "Tigres Negros", una rama del LTTE, que tenía encomendada la labor de entrenar y equipar a los soldados para este tipo de ataques, y compensar la falta de armamento pesado. Los Tigres Negros preparaban psicológicamente a hombres, mujeres y niños para que concluyeran su vida por un ideal étnico inmolándose en lugares públicos y concurridos con el fin de que la onda explosiva abarcará también a las personas que se encontraban a su alrededor. Acciones que tan solo no buscan producir temor en las esferas cercanas, sino que han permitido beneficios tanto políticos como económicos por presión, puesto que atentan contra per- 
sonas influyentes en la política y otras personalidades reconocidas, así como también reducen costos en el mantenimiento de la organización.

El primer atentado suicida realizado por este grupo fue el 15 de julio de 1987, cuando un tigre negro llamado capitán Miller entró con un camión lleno de explosivos en el campamento del ejército de Sri Lanka en Vadamarachi y explosionó la carga cerca de los cuarteles militares, causando, además de su propia muerte, la de unos 70 soldados de Sri Lanka (Pape, 2006, p. 175). Los Tigres Negros imponen a sus miembros una exigencia que nunca ha requerido ningún otro grupo militante destacado: que todos los miembros, hombres y mujeres, lleven una ampolla de cianuro, renovada cada varios meses, en una correa de cuero alrededor del cuello (Pape, 2006, p. 176). De tal manera, que si uno es capturado o prevé que pueda serlo, muerda la ampolla, para que muera en un par de minutos. Además, antes de las misiones nunca rebelan sus identidades, sin embargo, una vez muertos, se difunden los nombres de los suicidas en actos públicos de celebración, se publican las noticias en los periódicos tamiles, Kalathil y Erimalai, y en álbumes conmemorativos especiales que la organización se encarga de divulgar. Incluso, los propios suicidas encomiendan que su identidad sea relevaba, para ello llevan un carné de identidad plastificado con su fotografia, nombre y alias en inglés, cingalés y tamil, además el mismo contiene el siguiente mensaje: "Voy provisto de un gran explosivo. Si mi viaje se ve obstaculizado explosionaré la carga. Dejad que me vaya" (Pape, 2006, p. 177). Asimismo, la propia organización celebra ceremonias públicas anuales para venerar a sus mártires, erige monumentos en honor de los mismos cerca de las ciudades tamiles, y construyen estructuras cónicas conmemorativas con una plataforma para que la comunidad pueda dejar flores (Schalk, 1997, pp. 151-152).

Con más de 10.000 militantes, la organización se extendía por todo el territorio, distribuyéndose de norte a sur, en pequeñas células en el norte y el este, cada una con flota área, terrestre y marítima. Los métodos de reclutamiento no son muy restringidos, es más gracias a la labor social que realiza esta organización los tamiles consiguen reclutar una buena parte de sus miembros entre los ciudadanos más desfavorecidos. En este sentido, decir que en 1987 el LITE fundó la Organización de 
Rehabilitación de los Tamiles cerca de Jaffna, que ha proporcionado alimentos, agua, alojamiento, servicios-sanitarios y préstamos sin intereses a miles de familias e individuos (Pape, 2006, p. 47); en 1991 se inauguró el Centro para el Desarrollo de la Mujer, que ofrece ayuda humanitaria, formación profesional, asistencia psicológica y cuidados infantiles a mujeres y niños en una serie de centros que han ido construyendo desde entonces (Pape, 2006, p. 47); en 1992, los tigres instauraron un sistema policial y judicial en las zonas sometidas a su control, donde reclutan a mujeres como oficiales de policía y administradoras, con el fin de ampliar el papel de la mujer en la sociedad Tamil (Pape, 2006, p. 47); y en 1993 se fundó el Banco Eelam Tamil, que ofrece préstamos de bajo interés para fomentar las pequeñas empresas en diversos sectores, desde la producción de sal a la cría de marisco (Pape, 2006, p. 47).

No obstante, el ingreso en las brigadas suicidas es mucho más selectivo. Tal es así, que pese a que los guerrilleros del LTTE tienen la opción de integrarse a estos grupos, solo lo logran unos 150 o 200. Además, los Tigres Negros se entrenan en campos especiales, siendo adiestrados únicamente para el desempeño de su misión suicida. Así, el entrenamiento conlleva ejercicios físicos diarios, formación armamentística y clases políticas que hacen hincapié en el resultado final (Pape, 2006, p. 272), incluso, suelen hacer ensayos en el lugar previsto para los atentados y estudiar y analizar operaciones que ya han sido llevadas a cabo.

En estos mismos años, también se sumaron a esta práctica grupos terroristas de carácter islamista como, por ejemplo, "Hamás", "Al-Qaeda", "DAESH", entre otros. Hamás Harakat al Muqawama al-Islamiyya (Movimiento de la Resistencia Islámica) fue creada en Gaza en diciembre de 1987 por activistas de Hermanos Musulmanes y tomó forma durante la primera Intifada, donde, además de enfrentarse a las fuerzas de seguridad israelíes, desafió la primacía de la OLP gracias al movimiento nacional palestino. Hoy en día Hamás es la principal fuerza política en la Autoridad Nacional Palestina, y cuenta con una amplia red de servicios sociales que le garantiza el apoyo y simpatía de la ciudadanía. Entre sus objetivos está la liberación de todo el territorio de Palestina, mediante la destrucción de Israel, y la instauración de un Estado islámico. 
Hamás es una organización que está formada por un ala política y otra militar. Su ala política es la encargada de construir escuelas y hospitales en Cisjordania en la Franja de Gaza y brindar ayuda a la comunidad en asuntos sociales o religiosos. Su ala militar, las Brigadas Izzedine Al-Qassam, es la encargada de los ataques contra Israel. Las brigadas fueron creadas en 1992 bajo la dirección de Yahya Ayyash con el objetivo de crear una estructura militar que ayudase a lograr los objetivos de la organización islamista. Hasta 2004 han llevado a cabo numerosos atentados suicidas en el territorio israelí, causando hasta el momento decenas de muertos y daños de diferente consideración. Sus dos atentados suicidas más sangrientos: el de una discoteca en Tel Aviv en junio de 2001 (21 muertos y cien heridos) y el de Netanya (30 muertos) en marzo de 2002. Además de ese tipo de atentados, Hamás ha atacado pueblos y puestos militares israelíes con cohetes Qassam, morteros y fuego de fusilería desde las áreas fronterizas de Gaza. Así, Hamás cuenta con una sólida organización, que actúa en tres aspectos: militar, social y político, pero que son difíciles de fraccionar porque funcionan como un todo.

Los hombres bomba de Hamás son reclutados normalmente en las mezquitas, allí buscan hombres que posean tres cualidades: un intenso interés por el Islam, ausencia de antecedentes penales, para no levantar sospechas en la policía secreta israelí, y nervios de acero para llevar a cabo con éxito la misión (Kushner, 1996). Cuando surge la necesidad, los líderes de Hamás inician un debate sobre la muerte por Alá con pequeños grupos de jóvenes e invitan a los más interesados asistir a una clase especial de Hamás sobre estudios islámicos (Kushner, 1996). Al cabo de unas semanas, muchos alumnos de esas clases deciden voluntariamente ser terroristas suicidas, momento en el que Hamás inicia las investigaciones sobre los antecedentes de los voluntarios (Kushner, 1996). En esas clases, los reclutas dedican dos y cuatro horas diarias a la lectura y el debate sobre diversas partes del Corán (Hassan, 2001, p. 41). Los fragmentos hacen hincapié enemigo de la nación del Islam, la importancia de la fe, el deber de la yihad y los favores que brinda Alá a quienes considera más fieles (Hassan, 2001, p. 41).

Hamás también recurre a centros deportivos para reclutar militantes. Este es el caso del equipo de fútbol de la mezquita de Jihad en He- 
brón, afiliada a Hamás, el cual se convirtió en otro campo de cultivo de militantes. De estas filas salieron varios terroristas que fueron los responsables de diferentes atentados perpetrados por Hamás durante los seis primeros meses de 2003 (Levitt, 2007, p. 143). Entre las formas de hacerse presente, Hamás empleó una camiseta de un equipo de fútbol, la misma tenía un dibujo en el que una mano sostenía un hacha con una inscripción que decía: "Prepárate para el enemigo y para luchar contra la ocupación” (Levitt, 2007, p. 122).

En todo caso, cuando el guerrero es elegido para llevar a cabo un atentado suicida, y se acerca la fecha del mismo, se le lleva al cementerio para comprobar la serenidad del voluntario y su compromiso para realizar la tarea asignada (Pape, 2006). Se le dice que se prepare para la muerte tendiéndose durante varias horas entre las tumbas, ataviado con la misma mortaja blanca con capucha que se utiliza habitualmente para cubrir los cadáveres antes del entierro (Kelly, 2001). Los que permanecen impasibles aprueban el examen y son seleccionados para los preparativos finales, aunque como parte de la preparación, el suicida potencial debe regresar al cementerio para pasar más de 12 horas en una tumba recitando fragmentos del Corán (Kelly, 2001). Entretanto, otros miembros de la organización seleccionan el objetivo, construye la bomba o el chaleco suicida, realizan los preparativos para trasladar al terrorista hasta el objetivo (Kelly, 2001). Pero siempre se rechazan a los menores de 18 años, a quienes son el único sostén económico de la familia, también los casados y los que tienen responsabilidades familiares.

Así, cuando todo está preparado y programado los voluntarios suicidas son trasladados hacia el lugar donde tienen que llevar a cabo su cometido. Los voluntarios se inmolan en nombre de Alá, y por su acto tienen derecho a la vida eterna y llevar al paraíso a 70 miembros de su familia. Además, la organización paga el funeral, que incluye el entoldado de su casa, en la que los vecinos toman café y ofrecen las condolencias. Hamás también abona mensualidades a su familia y financia la atención sanitaria y la educación de sus hijos. Después del atentado, Hamás también se encarga de la distribución del video, donde se muestra las últimas palabras del "mártir". 
Al Qaeda es el movimiento religioso fundamentalista terrorista, fundado por Osama Bin Laden en los años ochenta. El origen de su nombre se debe a la manera informal que los combatientes islámicos se referían a los campos de entrenamiento que Bin Laden tenía en Afganistán. Al Qaeda es un grupo que está a favor de una "guerra santa" en contra de EE.UU. e Israel, guerra que comienza a partir de 1998 para lograr la "Umma" o la comunidad de creyentes. Para conseguir estos objetivos, y ante la inferioridad convencional, hace necesaria la autoinmolación (Pape, 2006, p. 57). En diciembre de 200l, al Zawahiri, el número dos de Al Qaeda, hacía hincapié en: la necesidad de concentrarse en el método de las operaciones de martirio como el modo más eficaz de causar daños al adversario con el menor coste posible de víctimas para los muyahidin (Pape, 2006, p. 57). Y para ello, se han utilizado los campos de entrenamiento, cuya finalidad era la preparación militar. Además, la mayoría de los candidatos hacían un curso "básico" de dos meses en el que solo se dedicaban dos semanas a la formación religiosa, cuyo objetivo era que los candidatos tuvieran una justificación común.

El resto de la formación básica de Al Qaeda se dedicaba a las destrezas militares necesarias para que un número reducido de combatientes matara a otras personas de modo efectivo, eficiente y, a ser posible, espectacular (Pape, 2006, p. 266). Así, el recluta pasaba por tres fases de formación militar: Primera fase: dura aproximadamente un mes, y en ella se enseña a los reclutas a utilizar una inmensidad de armas ligeras (pistolas, ametralladoras, rifles, etc.). Segunda fase: dura aproximadamente dos semanas, y los reclutas aprenden a manejar explosivos plásticos, dinamita y detonadores electrónicos, también se les instruía en el manejo de todo tipo de millas, como las antipersonales y las antitanques, incluso a emprender misiones de reconocimiento y preparación de planes para atentados concretos y Tercera fase: abarca aproximadamente las últimas semanas, donde el recluta se familiarizará con la utilización de armas pesadas (morteros, lanza granadas, misiles antiaéreos, entre otros) (Pape, 2006, p. 266).

DAESH, conocido como Estado Islámico, es un grupo terrorista insurgente de naturaleza fundamentalista islamista. Se encuentra formado por radicales fieles a Abu Bakr al-Baghdadi, el cual autoproclamó el 
califato desde la ciudad iraquí de Mosul, pidiendo con ello lealtad a los musulmanes de todo el mundo. En un primer momento, surgió como una organización terrorista próxima a Al Qaeda para hacer frente a la invasión de Irak en 2003. Hasta el punto que se unió a Al Qaeda bajo la tutela de Osama Bin Laden, pero sin embargo, aprovechó su expansión por Siria para proclamarse como Estado Islámico y tomar distancia de $\mathrm{Al}$ Qaeda, dado que su objetivo es crear un Estado islámico en las regiones sunitas de Irak y Siria. Desde entonces, la organización ha protagonizado su propia ofensiva contra Occidente, realizando ataques, principalmente, contra civiles en Europa. Sembrando el temor en todo el mundo. Además, es uno de los grupos yihadistas que se están valiendo de los suicidas para perpetrar atentados terroristas, valga de ejemplo, el ataque contra el aeropuerto Atatürk de Estambul, donde 239 personas resultaron heridas.

En este sentido, su estrategia es la siguiente, el DAESH se está dedicando a reclutar a menores de 18 años para que sean estos los que lleven a cabo los ataques suicidas. Estos jóvenes reciben el nombre de "cachorros del califato", y se están convirtiendo en la nueva generación de yihadistas. Tal es así, que según informe del Centro de Combate del Terrorismo de la Academia Militar de West Point (EE.UU.), el ISI está movilizando niños a una escala sin precedentes. Es más, en el mismo estudio se afirma que el $60 \%$ de las víctimas que pierden la vida en estas misiones son adolescentes.

El reclutamiento de estos nuevos voluntarios se consigue de la siguiente forma: se anima a las madres a sacrificar a sus hijos a favor de la autoproclamación del Estado Islámico, se secuestra a niños en orfanatos, o simplemente los adoctrina en los centros educativos. También, debido a la paupérrima situación por la que atraviesan numerosas familias en Siria e Irak hace que algunas de ellas envíen a sus hijos para integrarse en el DAESH para obtener algún tipo de ingreso destinado a la unidad familiar. Estos menores son internados en instalaciones como el Instituto de Raqqa, la capital oficial del autodenominado Estado Islámico, dado que el DAESH cuenta con su propio sistema educativo. El sistema educativo es diferente para las niñas que para los niños. Las niñas son instruidas ideológicamente y en la realización de labores domésticas para 
poder efectuar satisfactoriamente el doble papel de madres y esposas. En cambio, los niños reciben en un primer momento un adoctrinamiento de una versión distorsionada del Corán, y a partir de los 10 años hasta los 15 reciben un entrenamiento específico en el manejo de los distintos tipos de armas y que culmina con una ceremonia de graduación donde el menor debe decapitar a un prisionero.

Además, hay que tener en consideración otro hecho a la hora de hablar de los ataques suicidas, a pesar de lo que la mayoría pudiera pensar, este tipo de acciones no son patrimonio de la yihad islamista, sino que también es posible detectar este tipo de prácticas en otro tipo de organizaciones y en otras civilizaciones no islamistas. Aunque si es cierto, que es en estas sociedades islamistas donde esta táctica ha alcanzado sus perfiles más característicos y aterradores. No obstante, la organización que ha efectuado el mayor número de ataques suicidas ha sido el grupo etno-nacionalista, anteriormente mencionado, los Tigres de Tamil, en total ha ejecutado más de ciento sesenta acciones suicidas, e incluso, son responsables del impresionante atentado contra el World Trade Center de Colombo, cometido en 1997.

Asimismo, el Partido de los Trabajadores Kurdo (PKK) de inspiración marxista-leninista, también ha llevado a cabo veintiún acciones suicidas (Jordán, 2004, p. 26), contra edificios gubernamentales y objetivos militares turcos. Aunque hay que señalar que la campaña suicida del PKK es la menos agresiva, pues ha cosechado un promedio de dos muertos por atentado; además no buscan publicidad como en otras organizaciones, ya que no dejan ni videos ni testamentos ni poemas, ni nada por el estilo. Su origen suicida, a diferencia de otros grupos, se debe con toda probabilidad a su compromiso con su líder, Abdullah Ocalan, ya que durante su reclusión en la cárcel, pidió a sus seguidores que cometiesen atentados suicidas como medio de coacción para que el Gobierno turco lo liberase (Pape, 2006, p. 199). El método coercitivo fracasó y los atentados remitieron cuando Ocalan pidió a sus adeptos que renunciasen a tal procedimiento (Pape, 2006, p. 199).

La organización palestina "Brigadas de los Mártires de Al-Aqsa" es un grupo islamista y ha realizado más de una decena de atentados sui- 
cidas (Jordán, 2004, p. 26). Las Brigadas nacieron con el estallido de la Segunda Intifada en el 2000, tras los enfrentamientos del 29 de septiembre en la Explanada de las Mezquitas de Jerusalén. El nombre de este grupo está relacionado con la Mezquita de Al-Aqsa situada en Jerusalén, a pesar de ser un movimiento laico, se encuentran vinculadas al partido oficialista Fatah, aunque disfrutan de una gran autonomía. En todo caso, esta organización es responsable de decenas de ataques suicidas, además, es un grupo que cuenta con una unidad de suicidas mujeres.

Tabla 1. Organizaciones que emplean la táctica de misiones suicidas en el conflicto palestino-israeli

\begin{tabular}{|c|c|c|c|c|}
\hline Nombre & $\begin{array}{c}\text { Año de } \\
\text { fundación }\end{array}$ & Ideología & Región de operación & Vínculos \\
\hline $\begin{array}{l}\text { Hamás/ } \\
\text { Al } \\
\text { Qassam }\end{array}$ & 1987-1991 & Islam (suní) & Territorios, Israel & Irán, Siria \\
\hline $\begin{array}{l}\text { YIP/Al } \\
\text { Quds }\end{array}$ & 1979 & Islam (suní) & $\begin{array}{c}\text { Gaza (Ribera } \\
\text { Occidental) }\end{array}$ & Irán, Siria \\
\hline $\mathrm{Al} \mathrm{Aqsa}$ & 2001 & Nacionalista & $\begin{array}{l}\text { Ribera Occidental } \\
\text { (Gaza) }\end{array}$ & Al Fatah \\
\hline Hezbolá & 1982 & Chiíta & Líbano & $\begin{array}{l}\text { Irán, } \\
\text { Suiza }\end{array}$ \\
\hline Amal & 1975 & Chiíta & Líbano, Internacional & Irán, Siria \\
\hline Baaz-Lib & 1966 & Panárabe & Líbano & Siria \\
\hline SSNP & 1932 & Nacionalista & Líbano & Siria \\
\hline $\begin{array}{l}\text { Al Fatah/ } \\
\text { Tanzim }\end{array}$ & 1964 & Nacionalista & Israel, territorio & \\
\hline FPLP & 1967 & $\begin{array}{l}\text { Marxista, } \\
\text { Panárabe }\end{array}$ & Internacional/Israel & Siria \\
\hline
\end{tabular}

Fuente: (Gambetta, 2005, p. 176). 
Otra cuestión es que la gran mayoría atribuye las misiones suicidas al conflicto árabe-israelí. Aquí los protagonistas no son solo, como muchos pudieran pensar, Al-Qaeda, Hamás, Hezbollah, DAES, sino que también son partícipes muchos otros. La gran mayoría de las misiones suicidas relacionadas con el conflicto árabe-israelí tuvieron lugar en tres grandes zonas geográficas: Israel, los territorios ocupados (la Franja de Gaza y la Ribera Occidental) y el Líbano (primordialmente en el sur) (Gambetta, 2005, p. 126). Convirtiéndose estas en una herramienta recurrente en el conflicto israelí-palestino y en el conflicto de Oriente Medio en general, desde 1981. A este respecto habría que señalar que hasta el 2000, los ataques suicidas se producían principalmente en Cisjordania y la Franja de Gaza, solo a partir del 2001, las misiones suicidas se extendieron a todo el territorio israelí. Además, desde esas fechas la violencia también se extendió hacia el sur del Líbano.

En todo caso, los grupos que en este conflicto han empleado esta táctica han sido: Hamás/Al Qassam, Yihad Islámica Palestina (YIP)/Al Quds, Al Aqsa, Hezbolá, Amal, Baaz-Líbano, Partido Socialista Nacional Sirio (SSNP), Al Fatah, Tanzim y Frente Popular para la Liberación de Palestina (FPLP) (tabla 1). De Hamás, Hezbolá y Al Aqsa ya hemos hablado. Ahora vamos a hacer una pequeña referencia a las otras organizaciones que han utilizado el ataque suicida:

- La Yihad Islámica Palestina es un movimiento yihadista considerado terrorista, ya que su principal objetivo es la destrucción de Israel y su remplazo por un Estado Islámico en Palestina. Este grupo define a la yihad como una acción bélica contra los israelíes, además se oponen a otros gobiernos árabes por considerarlos poco islámicos.

- Las Brigadas de Al Quds es el brazo armado de la organización, así ha reivindicado su participación en numerosos ataques contra Israel, sobre todo atentados suicidas.

- El movimiento Amal es el más moderado de Shíite, y fue fundado, por el al-Sadr de Moussa el clérigo en 1974, para dar una mayor opinión para Shi ítes de largo descuidado de Líbano. Hoy 
en día esta fuerza política coopera con Hezbollah de Shi ítes y ha participado activamente en la guerra contra Israel.

- El partido Baaz-Líbano es una fuerza política nacionalista árabe, laico y radical socialista. Su ideología guarda ciertas similitudes a la ideología fascista, dado su discurso populista y su nacionalismo panarabista que casi se convierte en expansionista.

- El SSNP es una agrupación política creada en 1932 por el pensador Antun Sa'adeh. Su objetivo es construir a un gran Estado soberano que unifique la actual Siria con el Líbano, Palestina, Jordania, la Isla de Chipre, Irak y Kuwait, territorios que conforman la Siria histórica. Este partido ha dado a Siria constante ayuda dentro del Líbano, y disfruta de alianzas con otros partidos prosirios, tales como Hezbollah y Amal, y ha luchado activamente en la guerra civil libanesa, y el mayor defensor de que Hezbollah conserve sus armas.

- Al Fatah fue fundado por Yasir Arafat en 1959, y se unió a la OLP en 1968. Después de la Guerra de los Seis Días, los miembros de este grupo se refugiaron en Jordania, donde organizaron una serie de revueltas con los militares jordanos durante los años 1970-71. La invasión del Líbano en 1982 llevó a la dispersión del grupo en varios países árabes, como Túnez, Yemen, Argelia, Irak y otros, aunque algunos de sus miembros se mantienen activos llevando a cabo ataques terroristas.

- Tanzim es una facción armada del movimiento palestino Al Fatah. Este grupo fue formado en 1983 por Marwan Barghuti, un militante de Fatah durante la Primera Intifada, que decidió crear esta organización para evitar que las milicias de Hamás controlaran las calles, ya que $\mathrm{Al}$ Fatah era más bien un grupo de oficina. De esta manera, el Tanzim se convirtió en un movimiento de masas, con un ejército de jóvenes que declaraban su intención de sacrificarse por Palestina y Yasser Arafat. 
- El FPLP es una organización marxista-leninista palestina, que promueve el levantamiento de las masas palestinas para el retorno a Palestina, la libre determinación, y el establecimiento de un Estado Palestino. Y estos serán los pasos por seguir para derrotar a Israel, y liberar a todos los palestinos, y establecer así el Estado Palestino.

En definitiva, son unas acciones que llevan a cabo el bando más débil en conflictos caracterizados por una acentuada asimetría en el equilibrio de la fuerza militar (Atran, 2003; Pape, 2005). Y este tipo de organizaciones recurren a las misiones suicidas, como señala Merari (2005), cuando se ven arrinconados y temen por su sobrevivencia.

\subsection{La mujer "suicida"}

Entre el 20\% y 35\% de los ataques de terroristas suicidas a nivel mundial son perpetrados por mujeres (Singh, 2008, p. 2) y desde 1985 el fenómeno ha mostrado una tendencia al incremento. Tal es así, que desde 1985 al 2006, han habido más de 220 mujeres que han perpetrado actos de terrorismo suicida, 189 de ellas participaron en las organizaciones de Sri Lanka (75), Israel y los territorios ocupados de Palestina (67) y en el caso de Chechenia (47) (Schweitzer, 2006, p. 8). Por tanto, a partir de esta premisa se puede esperar que la incidencia de mujeres suicidas se vuelva cada vez más común y que más grupos recurran a esta estrategia (Enkerlin y Zatarain, 2011, p. 148). Ya que proporciona más ventajas que desventajas, dado que las mujeres consiguen unos efectos mediáticos, a nivel internacional, muy superiores a si el hecho estuviera ejecutado por un hombre; logran acceder a lugares limitados o vetados para los hombres, tanto por sufrir -en general-controles de seguridad menos exhaustivos que los hombres, como por su mayor facilidad para camuflarse en el medio, bien sea en un mercado, en un hospital o simplemente en la calle (Baños, 2008, p. 1).

Además, téngase en cuenta que en las sociedades menos evolucionadas las tareas que son habituales a las mujeres -como sirvientas, personal de limpieza, camareras, etc.- hacen que tengan acceso a ciertos 
lugares totalmente prohibidos para sus compañeros masculinos (Baños, 2008, p. 1); sus ropajes amplios y que cubren todo el cuerpo facilitan la ocultación de gran cantidad de explosivos, al tiempo que les posibilitan fingir estar embarazadas, para aún hacer los controles más superficiales (Baños, 2008, p. 1); requieren menos tiempo que los hombres para su entrenamiento, ya que tienen una convicción más firme y, al morir, se les paga menos a sus familias que a las de un mártir hombre (Patkin, 2004); causan más terror, ya que los atentados realizados por mujeres tienen una mayor repercusión mediática al existir una curiosidad desmedida por conocer la causas que le llevaron a efectuarlo, como si fuera una acción más violenta que cuando lo protagonizaba un hombre.

En cualquier caso, está claro, que las mujeres se han integrado activamente en la lucha armada. Así, han pasado de realizar funciones de apoyo (ayuda médica, provisiones, bastión moral, cargar las armas, entre otras) a unirse a la lucha activa. Tal es así, que tras la Segunda Intifada presentó tres características diferentes de la primera: una agenda con orientación de género (feminista) como alternativa a la agenda nacional del liderazgo hegemónico masculino; una maternidad alternativa y el fenómeno de las mujeres terroristas suicidas (Tzoreff, 2006, p. 16). Por ejemplo, en la Epístola Quinta de Al Qaeda se señalaba que era necesario que las mujeres se alzasen en guerra contra la nueva cruzada declarada por el mundo entero contra el Islam y los musulmanes (Guidère y Morgan, 2007, p. 193). En este mismo sentido, también se manifestó Yasser Arafat, en enero de 2002, cuando instó públicamente que las mujeres se unieran como iguales a la lucha contra Israel, aplicando por primera vez el término de mártir para las mujeres.

Pero pese a esto, y contrario a lo que la gente podría pensar, la religión no es un factor fundamental para cometer terrorismo suicida (Enkerlin y Zatarain, 2011, p. 169). Es decir, los fines políticos independentistas de las distintas organizaciones no necesariamente van de la mano con un fervor religioso (Enkerlin y Zatarain, 2011, p. 169). Si bien en el caso palestino se pueden excusar las misiones suicidas bajo este fundamento, no existe evidencia alguna que las Tigresas Negras de los Tigres de Liberación de Tamil Eelam o las 'Viudas Negras' de Chechenia se ba- 
sen meramente en motivaciones religiosas (Enkerlin y Zatarain, 2011, p. 169). Tampoco se pueden deber únicamente a cuestiones psicológicas, sino más bien a factores sociales, culturales y personales (Pedahzur, Perliger y Bialsky, 2007). Por ejemplo, la pérdida de seres cercanos como amigos o familiares puede producir un deseo de venganza, por la cual se buscan los medios para 'castigar' a los responsables y subsanar sus heridas. También, el sufrimiento al que es sometida su comunidad por los constantes enfrentamientos y conflictos puede hacer que el individuo esté dispuesto a tomar medidas sin importar el costo (Pedahzur, Perliger y Bialsky, 2007). A esto se puede sumar su disposición a cumplir con las misiones suicidas por el compromiso que tienen hacia determinada comunidad u organización y hacia sus metas. Por tanto, como se puede comprobar, los ataques suicidas no son, como algunos se empeñan en defender, acciones irracionales, sino que se realizan por decisión propia y siguiendo una estrategia lógica en pos de un fin específico (Enkerlin y Zatarain, 2011, p. 152):

- Muchas mujeres consideran el combate como una forma de escapar de la vida que tiene predestinada (cuidar a sus hijos y marido, realizar las labores de la casa, etc.), ya que cuando se convierten en mujeres bombas no es solo en nombre de su nación o líder sino de su género (Beyler, 2003).

- Muchas mujeres se integraron en este tipo de prácticas suicidas debido a la escasez de potenciales de los reclutas masculinos. Por ejemplo, los Tigres de Liberación comenzaron a buscar mujeres que fueran políticamente activas, participaran en demostraciones públicas contra la opresión gubernamental o que estudiaran en la universidad (Jordan y Denov, 2007, p. 46), a cambio se les ofrecía una forma de retribución y de venganza. Así, la mayoría de las mujeres de este grupo parecen unirse al movimiento voluntariamente por lealtad nacionalista, pero también para escapar de hogares abusivos, pobreza y violencia sexual (Jordan y Denov, 2007, p. 46).

- Otras sienten la necesidad de hacer algo por el resto de su comunidad y estaban seguras de poder vivir en paz solamente si lograban la independencia (Jordan y Denov, 2007). Por ejemplo, muchas mujeres palestinas han justificado el terrorismo suicida diciendo que sacrificar una vida bajo la ocupación israelí no es realmente un sacrificio, debido a las 
condiciones deplorables en las que viven, la agresión hacia ellos, su país y sus lugares sagrados (Allen, 2006, p. 50).

- Algunas mujeres lo hacen por situaciones personales difíciles (divorciadas, repudiadas, infértiles, madre soltera, promiscuas, víctimas de una violencia sexual, manchado el honor de la familia, etc.), ya que convertirse en mártir se constituye como la única opción para recobrar el honor, si no llevarán a cabo estas operaciones, serían parias sociales y estarían muertas para su comunidad. Por ejemplo, de acuerdo con Women for Peace in Colombo, ONG de Sri Lanka, la idea del sacrificio como algo noble es prevaleciente en la cultura Tamil, y el sacrificio de una mujer suicida se considera casi una extensión de la maternidad (Knight y Narozhna, 2005, p. 147). Para Suva, miembro de esta ONG, "actuar como una bomba humana es entendido y aceptado como una ofrenda por parte de una mujer que no puede ser madre. La familias de mujeres que han sido violadas frecuentemente las instan a que se unan al LTTE con este propósito" (Knight y Narozhna, 2005, p. 147). En Chechenia, se cree que las "zombis" se convertían en mujeres bombas como consecuencia de haberse quedado embarazadas sin estar cansadas, algo inaceptable en esa sociedad (O'Connor, 2007, p. 96).

- También hay mujeres que entran en la lucha por cuestiones emocionales y psicológicas. Por ejemplo, las "viudas negras" de Chechenia han participado en ataques suicidas por la pérdida de sus esposos, hermanos, hijos y familiares, pero también por la propia presión social. Como sostienen algunos analistas, como Kemoklidze (2009) y Knigh y Narozhna (2005), hablan de un cambio en el rol femenino y de un mayor involucramiento, derivado de una impotencia social y el apoyo en ideas nacionalistas.

En cualquier modo, los primeros casos documentados de mujeres suicidas que se puede encontrar se producen en los Tigres Tamiles, que es uno de los pocos grupos terroristas que tienen institucionalizada la táctica del suicido como forma habitual del ataque. Es en 1984, tras una campaña de interrogatorios y detenciones de hombres tamiles por parte del Gobierno, cuándo nacen los Pájaros de la Libertad, la guerrilla femenina (Martínez Varela, 2010, p. 9). Este grupo ha centrado sus ataques tradicionalmente en altos cargos políticos, siendo el más exitoso y conocido el asesinato en 1991 del primer ministro de la India, Rajiv Gandhi, a manos de una joven Tamil que se inmoló durante un mitin previo a las elecciones indias (Martínez Varela, 2010, p. 9). Pero los Tigres de 
Tamiles no es el único grupo terrorista que han empleado mujeres para llevar a cabo sus ataques suicidas. En Chechenia las mujeres terroristas pueden dividirse en dos grupos: las "viudas negras" y las "zombis". Las primeras son unas terroristas suicidas que llegan a esta situación tras la muerte de su pareja, y las segundas son unas mujeres que son forzadas o engañadas para convertirse en terrorista por hombres chechenios $\left(\mathrm{O}^{\prime}\right.$ Connor, 2007, p. 96).

Incluso, Hamás que en un principio no estaba por la labor de incorporar mujeres a su lucha, o por lo menos así lo había expresado su fundador, Sheikh Ahmed Ismail Yassin, cuando afirmó que su organización no necesitaba mujeres en su yihad, ya que "la mujer es la segunda línea de defensa en la resistencia a la ocupación” (O’Connor, 2007, p. 97). En la misma línea, O’Rourke (2008) puso en boca del mismo Yassin, al comienzo de la Segunda Intifada en 2000, que una mujer mártir es problemática para la sociedad musulmana. Un hombre que recluta una mujer está rompiendo la ley islámica. De hecho, Hamás rechazó a Darin Abu Eisheh, la segunda mujer palestina que cometió un atentado, en 2002, cuando actuó en nombre de la Brigada de los Mártires de al-Aqsa (Baños, 2009, p. 2). Sin embargo, pese a ello, el 14 de enero de 2004, Reem Al-Rayasha hizo explosionar una bomba suicida en un paso fronterizo de Jerusalén, y tras el ataque, Sheikh Yassin informó que Hamás había decidido emplear una mujer para cometer el atentado, debido a las cada vez mayores dificultades para conseguir hombres para realizar las acciones operativas (Baños, 2009, p. 2).

Pero no solo grupos terroristas han sido partidarios de esta práctica, sino también organizaciones políticas como el Partido de los Trabajadores del Kurdistán (PKK). En esta organización los ataques suicidas desde 1996 fueron realizados por mujeres. Además, según nos indica Beyler (2003) desde sus inicios, el 66\% de los atentados suicidas cometidos por miembros del PKK fueron ejecutados por mujeres. En Palestina, el primer atentado suicida realizado por una mujer, lo organizó el Partido Sirio Nacional Socialista (Beyler, 2003). Es más, del total de 12 ataques suicidas cometidos por este partido, las mujeres han tomado parte en seis de ellos (Bloom, 2007). 


\subsection{El reclutamiento, la motivación y el perfil de los voluntarios "suicidas" islamistas}

En todo acto de terrorismo suicida se esconde un reclutador, cuya labor es emprender pacientes búsquedas destinadas a detectar posibles mártires entre aquellos que tengan un perfil psicológico influenciable, de forma que puedan incorporar ciertas pautas del sistema de creencias (ideología/religión) del grupo. También, se tendrá en cuenta que los mismos formen parte de un entorno cultural favorable al objetivo y que, en lo posible, su historia personal y familiar fuera acorde con las expectativas del grupo. Sin embargo, un porcentaje de los recluidos provienen de familias fragmentadas, o de procesos vinculados a conflictos no resueltos socialmente, o frustrados en su vocación, cuando no, marginados sociales.

El reclutador acude a mezquitas, cibercafés, centros educativos, foros de internet, blogs, etc., es decir, centros donde se reúnen los jóvenes, y allí se dedican a observar los comportamientos de las personas que acuden a ellos, con el fin de seleccionar a los futuros candidatos. En principio, son rechazados los menores de 18 años, quienes son el único sostén económico de la familia, los casados y los que tienen responsabilidades familiares. Además, no escogen a personas con un cuadro clínico suicida, sino jóvenes normales, que incluso tienen un trabajo remunerado, pero que destacan por su espíritu religioso y por su odio apasionado hacia el enemigo (Jordán, 2004, p. 28). Y todo porque, la apariencia y los rasgos de la personalidad del mártir suicida juega un papel importante.

Después el reclutador empezará a entablar algún tipo de conversación con aquellos, que considera que pueden cumplir con el perfil físico y psicológico de mártir suicida. Discuten sobre ciertos temas, para conocer su posicionamiento del futuro candidato hacia temas claves, y si lo cree pertinente lo seleccionará. Una vez que se elige al candidato, el grupo terrorista o insurgente le asignará dos asistentes para que permanezcan junto al mártir potencial todo el tiempo que sea posible. Ellos deben avisar de cualquier signo de duda que pueda tener el joven recluta, y en caso de producirse alguna vacilación se envía de inmediato 
a un instructor adulto para que solucione el problema. Para ello, se le pregunta repetidamente por qué desea convertirse en hombre bomba, por qué quiere hacer algo que es condenado, cuáles son sus motivos reales, etc. Incluso, si el candidato al martirio es un antiguo miembro del grupo, necesita tener muy claro que en tales operaciones no se puede dar marcha atrás.

Por tanto, el primer paso es conocer las motivaciones que pueden impulsar a que una persona se convierta en un hombre bomba. Lo normal es que existan motivaciones personales (psicológicas, políticas, religiosas, entre otras) y sociales (psicosociales, políticas, religiosas) para presentarse como voluntario para este tipo de acciones. Aunque no todos los estudios están de acuerdo con esta cuestión, por ejemplo, Bloom (2005b) sostiene que se hace evidente que las mujeres suicidas obedecen sobre todo a razones muy personales, de modo diferente a los hombres, que suelen reaccionar, en su opinión, principalmente por motivaciones religiosas o nacionalistas. Tal es así, que algunos consideran que la motivación principal es el fanatismo religioso, ya que parece muy fácil convencer a un adolescente impulsivo y sin experiencia de que, si se ata unas cuantas cargas de dinamita a la cintura y aprieta un botón, traspasará las puertas del Paraíso y se acostará con vírgenes (Pape, 2006). En este mismo sentido, manifiesta Boaz Ganor (2000), que considera que la razón por la que cometen ataques suicidas los islamistas, es en primer lugar, de origen religiosa, combinada con un nacionalismo extremo, pero no lo hacen por desesperación personal.

Otros consideran que el factor religioso no es tan determinante, y en cambio si lo es la resistencia nacional frente al enemigo externo. Ahí, muestran el ejemplo de los ataques suicidas PKK, que no guardaba ninguna relación con el tema religioso. Incluso, también se podría hablar de la defensa nacionalista como una de las causas que alegan las mujeres para convertirse en candidatos suicidas. Según O’Rourke (2008), el 95\% de los ataques suicidas cometidos por mujeres han tenido lugar en el contexto de una campaña militar contra fuerzas ocupantes extranjeras, con el objetivo de mantener o recuperar la soberanía territorial para su grupo étnico. Es más, en la "Carta abierta" de Hezbolá, se decía que sus 
"objetivos grandes y necesarios" eran "poner fin a la ocupación extranjera y adoptar un régimen libremente elegido por el pueblo del Líbano" y "expulsar definitivamente del Líbano a los norteamericanos, franceses y aliados" (Pape, 2006, p. 47).

Otra, es la venganza, como consecuencia de la muerte de un pariente o un miembro cercano en el enfrentamiento con el adversario, bien fuera directamente en acción, al ser capturado o durante el cautiverio. La presión social es otro factor para tener en cuenta a la hora de analizar las motivaciones que las lleva a integrarse en acciones suicidas, aunque este factor es más normal en las mujeres que en los hombres, como ya se hizo alusión en el apartado anterior. Téngase en consideración que algunas mujeres ven en el acto suicida una manera de poner fin a semejante situación, al tiempo que garantizan la supervivencia de su familia, ya que lo normal es que sea acogida por el grupo ideológico en cuyo beneficio haya realizado la acción terrorista.

Otra, son los honores de todo tipo que reciben las familias y los terroristas a título póstumo, lo que contribuye a que algunos se lancen a emular a estos terroristas suicidas en la búsqueda del mismo reconocimiento social y económico, que eleva su estatus y su reputación.

Otra, a la que muchos aluden, es la profunda pobreza en la que viven los candidatos, y todo porque el terrorismo suicida ha surgido en las sociedades del tercer mundo. Aunque, como han mostrado algunos investigadores, la pobreza es una causa insuficiente para explicar el terrorismo suicida (Krueger y Maleckova, 2002). Los países que sufrieron el terrorismo suicida desde 1980 hasta 2001 no son, ni por asomo, los menos ricos del mundo, es más, algunos podrían clasificarse como sociedades de "renta media", cuyos habitantes no tienen una esperanza de vida inferior a la de los estadounidenses (Pape, 2006, p. 33).

En todo caso, según un estudio realizado por Kimhi y Even (2003) existen cinco prototipos de terroristas suicidas: a) el religioso, b) el psicológicamente devastado, c) el nacionalista, d) el manipulado y e) el circunstancial o random. En el primer caso, el prototipo está representado por terroristas dispuestos al martirio, se tratan de personas que tuvieron 
en su infancia o adolescencia una fuerte preparación religiosa. Por lo general, se caracterizan por ser hombres solteros y jóvenes, que pertenecen a familias humildes, y que han participado de alguna manera en la Primera Intifada. En el segundo caso, se trata de jóvenes reclutados que se encuentran en estado de profunda depresión, y cuya vida ha estado marcada por hechos extraordinariamente dolorosos o traumáticos, por fatalidades de diverso tipo, que han terminado minando su fortaleza emocional, y se encuentran ansiosos de venganza. El tercer caso, se trata de fanáticos militantes, que tienen cierta formación política. En el cuarto caso, son jóvenes que están sujetos a fuertes presiones familiares o grupales, de la más diversa índole. Y en el quinto y último lugar, se trata de terroristas que optan por el suicidio por coyunturas fortuitas, curiosidad por el tema, deseos de trascendencia, carencia de perspectivas para la realización personal o dilatación de proyectos personales por causas ajenas a él (Kimhi y Even, 2003).

Hasta ahora se ha hecho mención al reclutamiento de voluntarios, pero en otras ocasiones, este reclutamiento se realiza sobre personas que no desean formar parte de este tipo de prácticas, pero que se ven obligadas a ello, ya que se encuentran sometidos a chantaje. Téngase en cuenta que, por ejemplo, la violación es una de las mayores vergüenzas que puede sufrir una mujer, ya que cuando una de las víctimas sufre una agresión sexual es repudiada, incluso castigada, recibiendo latigazos por haber provocado el asalto. Otro método es coacción social y psicológica, por ejemplo, tras haber estado involucrada en una relación personal ilícita. Este tipo de coacción es utilizado habitualmente por el Fatah-Tanzim, para ello, se inicia un proceso de seducción mediante el cual las mujeres jóvenes se ven inmersas en relaciones ilícitas. De esta forma, se busca presionar emocionalmente a las mujeres con el objetivo de convencerlas para que acaben su vida de una forma admirable, puesto que la revelación pública de su "incidencia" podría constituir una ignominia para el honor de sus familias. Incluso, en otras ocasiones, se ha llegado a pagar a padres para que cedan a sus hijos para la causa y se conviertan en suicidas. 
Respecto al perfil de este tipo de individuos habría que destacar, que hasta el 11-S se creía, generalmente, que el típico suicida con bomba en Oriente Medio era un hombre joven, soltero y desempleado, quizás expuesto a privaciones sexuales, para quien un movimiento religioso podría llenar un vacío que de otra manera ocuparían la familia y el trabajo (Moghadam 2003, p. 76). Pero estos atentados cambiaron la percepción sobre el perfil de los suicidas, ya que los que participaron en esta acción terrorista fueron 19 jóvenes de edades comprendidas entre los 20 y los 33 años, además mientras que unos estaban desempleados otros trabajaban y habían cursado estudios superiores, unos atendían regularmente a la oración y tenían observancia rigorista del Islam, mientras que otros consumían alcohol y drogas. Ni siquiera el patrón de reclutamiento y de adoctrinamiento era similar, ya que unos fueron captados en campus universitarios y otros en mezquitas, unos en Arabia Saudí y otros en Alemania (Merlos, 2008, p. 49). Aunque, algunos especialistas se empeñan por seguir manteniendo el perfil clásico de los terroristas suicidas. Así, por ejemplo, Boaz Ganor (2000) sostiene que el perfil de los atacantes suicidas es el siguiente: jóvenes, normalmente entre 18 y 27 años; solteros, desempleados; provenientes de familias pobres; con enseñanza media completa, muchos, incluso son o han sido estudiantes de los centros islámicos fundamentalistas de Gaza y la Cisjordania.

Si bien es cierto, que el terrorismo suicida se ha nutrido en gran parte de los estratos más desfavorecidos, no es menos cierto que en la amplia lista de aquellos que han "accedido al martirio" se pueden hallar individuos procedentes de familias acomodadas y medias, que vienen a modificar el perfil clásico del terrorista suicida. En este sentido, Nasra Hassan (2001) ha elaborado un perfil que es muy diferente del estereotipo que todos conocemos, ya no se trata de jóvenes desempleados, con escasa educación, provenientes de familias pobres, solteros, desesperados o deprimidos. Ahora, los candidatos a suicidas son jóvenes de entre los 18 y los 38 años. Muchos vienen de la clase media, y a menos que sean fugitivos, todos tienen trabajos pagados. Algunos provienen de campos de refugiados, otros son miembros de familias plenamente normales. Suelen tratarse de personas educadas y serias, que normalmente son consideradas como modélicas. Todos son profundamente religiosos, 
conocen de memoria largas secciones del Corán y son muy versados en aspectos de la ley y la práctica islámica.

Tal es así, que tan solo se tendría que analizar el perfil de algunos de los terroristas que llevaron a cabo las acciones del 7-J. Por ejemplo, Sidique Khan, de 30 años, estaba casado y tenía un hijo de 8 meses. Era un profesor de primaria en una escuela en la que conseguía, en poco tiempo, integrar a cristianos, musulmanes y a los chicos que, en general, presentaban problemas de adaptación (Merlos, 2008, p. 49). Shehzad Tanweer, de 22 años, era licenciado en Ciencias del Deporte por la Universidad Metropolitana de Leeds y trabajaba en el restaurante de su padre vendiendo pescado y comida rápida. Su familia era originaria de Pakistán, permanecía muy unida y mantenía una situación acomodada en el norte de Inglaterra, lo que daba idea de los dos mercedes aparcados en la puerta de su domicilio (Merlos, 2008, p. 49). El jamaicano Lindsey Germanine se había convertido al Islam cuatro años antes de perpetrar la masacre, y había visitado EE.UU. en varias ocasiones; estaba casado y tenía un hijo, era un apasionado de lucha libre, solía ir al gimnasio frecuentemente, escuchaba música por la noche, conducía el coche a toda velocidad para desgracia de sus vecinos (Merlos, 2008, p. 49). En definitiva, con esta pequeña descripción, únicamente se quería demostrar la variabilidad de perfiles que puede haber entre los terroristas que realizan una misma operación, incluso, pueden responder a motivaciones diferentes.

\subsection{La preparación de un atentado "suicida" islamista y su ejecución}

En la dinámica de las misiones suicidas convergen dos niveles de actores: en primera instancia, se encuentran los perpetradores del ataque, es decir, los individuos que sacrifican su vida, mientras que, por otro lado, se hallan los organizadores, quienes instan y facilitan el armamento para alcanzar su cometido (Knight y Narozhna, 2005, p. 151, citado por Enkerlin y Zatarain, 2011). De nuevo, esto indica que este tipo de acciones no son actos irracionales sino racionales y perfectamente planificados que buscan el desgaste, el chantaje y las concesiones. Así, los 
organizadores son los que marcan el inicio y el final de las acciones, tras haber fijado los objetivos tácticos y estratégicos que se deben alcanzar. Además, son estos los que diseñan y controlan las fases para preparar a un suicida: identificación, reclutamiento, persuasión, conservación de la preparación y potenciación de ese estado mental, entrenamiento para la familiarización con la carga explosiva a utilizar y disposiciones finales previas al atentado como la oración para la purificación, la preparación de un testamento o la grabación de una reivindicación (Merlos, 2008, p. 78). Por lo que juegan un papel crucial tanto en el reclutamiento como en la planificación del ataque.

En todo caso, lo primero que hay que hacer es reclutar y seleccionar a los voluntarios que van a dar la vida en la acción suicida. Después, el organizador y la cúpula dirigente decidirán sobre cuál es el objetivo para atacar, y recopilarán toda la información necesaria sobre este para diseñar la operación y garantizar su éxito, siempre desde el parámetro de no atacar una escuela o un hospital. Para ello, todos los grupos disponen de una unidad de vigilancia, cuya misión es recabar información para determinar las carencias o faltas de seguridad del adversario, los objetivos y la planificación de la forma de ataque según el objetivo elegido. A continuación el mártir suicida deberá ser entrenado para llevar a cabo la operación, y esta se puede prolongar durante varias semanas o, incluso, meses, pero también podría ser simplemente unos días o varias horas. Durante la misma, el candidato a suicida recibe constantes recordatorios por las razones o motivaciones por las que se encuentra allí. Lo esencial es conseguir aislarle física y psicológicamente del entorno, como una manera de evitar influencias sociales que puedan ir en contra del éxito de la operación. Para ello, los adiestradores procuran que solo tengan contacto con sus compañeros de misión y únicamente accedan a las fuentes de financiación que la organización considere oportunas (Merlos, 2008, p. 83). Es un proceso de conversión en toda regla, que sigue unos pasos que van de la acumulación de tensiones internas y malestar, las perspectivas de resolver el problema desde la religión, la búsqueda decidida y prioritaria de la vía redentora, la identificación del Principio Divino como un punto de inflexión para una nueva vida, establecimiento y asentamiento de lazos afectivos con un nuevo entorno de individuos 
en el estado psicológico similar, la neutralización de las influencias externas a ese entorno, y la disposición a cumplir una misión que sintonice con los nuevos principios asimilados (Merlos, 2008, p. 82).

Cuando las circunstancias obligan a abreviar el tiempo de aislamiento físico o lo impiden absolutamente, los reclutadores tratan de controlar las relaciones sociales de los terroristas, limitando sus contactos con personas, grupos e instituciones no vinculados a la organización; durante su aleccionamiento, los terroristas leen con frecuencia aquellos pasajes del Corán en los que se glorifica el martirio y les son descritos los beneficios de la ulterior vida en el Paraíso (Merlos, 2008, p. 83). Además, se les da a conocer las recompensas que están reservadas a aquellos que se convierten en mártires de la yihad, es decir, su salvación con base en una serie de privilegios:

1. Los pecados serán perdonados: Alá “os perdonará vuestros pecados". En este sentido, una cita de un tradicionista añade: "Aquel que luche en la senda de Alá será salvado del Infierno".

2. Las puertas del Paraíso están abiertas de par en par. Alá no solo "os hará entrar en los jardines, sino que tendrán un trato preferente en el Paraíso” (Guidère y Morgan, 2007, p. 130).

3. Se le redime de los tormentos del sepulcro.

4. Se le ofrece seguridad ante el temor del infierno.

5. Se coloca sobre su cabeza una corona de gloria, uno de cuyos rubíes vale más que el mundo y todo lo que en él existe.

6. Se casa con setenta y dos huríes de ojos negros, y se le acepta su intercesión por setenta de sus parientes. Además, se le hace ver que "si los enemigos aspiran a los bienes de la vida, nosotros aspiraremos al encuentro con Alá, y a él entregaremos la vida" (Guidère y Morgan, 2007, p. 87).

Es una forma de lograr que el suicida supere definitivamente su miedo a morir, gracias a un proceso intenso de mentalización, donde juega un papel vital los rezos, el ayuno, el visionado de videos del testimonio de otros mártires y de ataques perpetrados contra su pueblo. De ahí, 
que sea fundamental para acometer estas misiones que la organización cuente con agentes de influencia muy capacitados que realizan un trabajo misionero y que sean capaces de captar y condicionar las actitudes y las conductas de unos jóvenes a los que inculcan la idea de que el sacrificio personal y espiritual llevado al extremo es el único medio de restaurar la dignidad del Islam y salvar al mundo de la corrupción moral y de la tiranía de Occidente (Merlos, 2008, p. 82). Así, parece importante destacar que "el martirio", en este caso, ejercería una triple función (y aquí el sentido circular en el análisis del discurso): la de "mensaje" que lleva implícito un llamado de atención a un destinatario que, en este caso, es el enemigo israelí; la de constituirse en "modelo" para que otros tomen una actitud similar, dando con ello cumplimiento al imperativo de hacer la "guerra santa" al pueblo de Israel; y la tercera dimensión que es la de "ofrenda" al Ser supremo para que le posibilite la entrada en ese otro mito al que denominan "Cielo" o "Paraíso" (Erramouspe, 2010).

Pero la preparación del candidato no solo implica una redefinición espiritual sino también otros muchos elementos. Por ejemplo, a los futuros mártires se les instruye cuidadosamente sobre cómo tratar a los enemigos antes de llevar a cabo la operación, también se les informa de todas las precauciones de seguridad que debe tomar, se les adiestra en el manejo de explosivos y en tácticas militares, se les prepara físicamente para adquirir destreza y resistencia, entre otras. No obstante, como la acción suicida solo implica la detonación de un explosivo, no se precisa una larga o compleja formación. Ni tampoco de particulares exigencias de fuerza física ni habilidades concretas, como requeriría el combate cuerpo a cuerpo. En todo caso, la preparación del candidato a suicida requiere una preparación psicológica, militar y cultural.

Una vez que el candidato está preparado para llevar a cabo la operación. El organizador ordena iniciar un proceso de seguimiento que puede durar de una a cuatro semanas, aunque en ocasiones es necesario realizar un seguimiento de cuatro o cinco meses de seguimiento. Después, el organizador comunicará al candidato el lugar, el objetivo, las personas objetivo del ataque, incluso desde donde se puede llegar a ellos, en qué punto parar para la ejecución, dónde dormir, cuándo empezar a disparar, cuándo estarán las personas, además se le proporcionará todo 
el material necesario para llevar a cabo la acción tal como ha sido planificada (Ibrahim, 2010, p. 28).

En este sentido, lo primero que habría que mencionar es que existen diferentes procedimientos para llevar a cabo una operación suicida. La elección depende de los recursos disponibles para el grupo, el nivel de daño que se desea causar, y la identidad del objetivo (De la Corte y Giménez-Salinas, 2010, p. 15). Centrándose en las tendencias recientes, que pueden dividirse en dos: 1) los artefactos explosivos improvisados (Improvised Explosive Device - IED), que a su vez se dividen en tres categorías: maletines o mochilas u otros objetos portados por el atacante; chaleco o cinturón cargado por el atacante; y bomba de mano o granada llevada por el atacante; y 2) los vehículos dirigidos improvisados como artefactos explosivos (Vehicle Borne Improvised Explosive Device - VBIED) estos pueden ser coches, camiones, aviones, barcos o trenes.

El tipo de material utilizado para este tipo de ataques suicidas son a menudo explosivos poderosos, tales como TNT o C4 (típico en Irak), por lo general complementado con metralla, los rodamientos de bolas o las uñas (Gill, 2007). Algunos cinturones suicidas están dotados de un trasmisor de radio que permite la detonación a distancia de un teléfono celular (Gill, 2007). Esto está ideado para que el atentado sea exitoso, ya que si el mártir sufre dudas o algún percance o fallo, pueda ser accionado el dispositivo por el planificador de la acción. Téngase en cuenta que muchos suicidas son incapaces de activar el sistema de denotación porque el miedo les bloquea. Por otra parte, si el objetivo del atentado es causar muertes civiles, el mártir se mezclara entre la población en un lugar que esté muy concurrido, y una vez allí accionará el dispositivo y se inmolara. En otras ocasiones, se han empleado a varios suicidas en acciones coordinadas, para garantizar un mayor daño, o simplemente para asegurar el éxito de la acción. Otras veces, los suicidas cargan sus explosivos en los vehículos para estrellarlos contra sus objetivos (VBIED, vehículos transmitidos por los artefactos explosivos improvisados) (De la Corte y Giménez-Salinas, 2010, p. 15). Normalmente se emplean varios coches, uno para distraer y centrar la atención del público, y otro para realizar la operación. Pero este procedimiento es mucho más caro que el anterior. También en este tipo de ataques suicidas se han utilizado avio- 
nes, como en los atentados producidos el 11 de septiembre de 2001 contra las Torres Gemelas. Pero eso requiere una mayor complejidad, un entrenamiento específico en el pilotaje, y una mayor preparación para hacerse con una aeronave civil con tripulación. Otro método puede ser a través de barcos, pero este, al igual que en el caso anterior, es más complejo y caro que los dos primeros. Eso sí, ambos guardan relación con los kamikazes japonés, que se valían de aviones y de lanchas para atacar y contrarrestar las fuerzas del enemigo.

Tabla 2. Los procedimientos que llevan a cabo algunos grupos

$\begin{array}{ccccc}\text { Grupo } & \text { Humano } & \text { Vehicular } & \text { Avión } & \text { Embarcación } \\ \text { Brigadas Al-Aqsa } & \text { Sí } & \text { Sí } & \text { No } & \text { No } \\ \text { Al-Qaeda } & \text { Sí } & \text { Sí } & \text { Sí } & \text { Sí } \\ \text { Chechenios } & \text { Sí } & \text { Sí } & \text { No } & \text { No } \\ \text { Hamas } & \text { Sí } & \text { Sí } & \text { No } & \text { No } \\ \text { Hezbolá } & \text { Sí } & \text { Sí } & \text { No } & \text { No } \\ \text { PKK } & \text { Sí } & \text { No } & \text { No } & \text { No } \\ \text { PIJ } & \text { Sí } & \text { Sí } & \text { No } & \text { Sí } \\ \text { LTTE } & \text { Sí } & \text { Si } & \text { No } & \text { Sí }\end{array}$

Fuente: (Bunker y Sullivan, 2005, p. 69).

Siglas: PIJ: Jihad Islámica Palestina, PKK: Partido de Trabajadores de Kurdistán; LTTE: Tigres de Tamil.

Todo, porque el 90\% del éxito de la operación suicida depende de varias condiciones: un nivel máximo de secreto, el reconocimiento de la escena, y la adquisición de materiales y de información sobre el objetivo (De la Corte y Giménez-Salinas, 2010, p. 14). La familiaridad con la ubicación del ataque, y la obtención de información sobre el objetivo, facilita la anticipación de las acciones justo antes del ataque y la planificación del suicidio (De la Corte y Giménez-Salinas, 2010, p. 14). El secreto garantiza la preservación del factor sorpresa, que es crucial para 
la mayoría de las operaciones. De ahí, que el compromiso del candidato con el secreto sea absoluto, tal es así, que la mayoría de ellos no dejan ninguna señal que indique su intención de llevar a cabo la operación de martirio. Hasta tal punto, que en la mayoría de los casos las acciones que son llevadas a cabo por los suicidas sorprenden a la propia familia y amigos. Por ejemplo, Mahmoud, hermano del mártir suicida palestino Ibrahim Sarahneh, no creía que su hermano fuera el que ejecutó una operación cualitativa en Ashkelon, el 25 de febrero de 1996. Manifestó en este sentido que: "Pocos días antes de su martirio había hecho los últimos retoques en su casa en preparación para su matrimonio", y agregó: "No estaba nunca fuera de casa" (Ibrahim, 2010, p. 57).

En todo caso, después de la acción suicida, el organizador es el encargado también de diseñar la operación de propaganda y de guerra psicológica que precede al atentado. El componente propagandístico es esencial para la organización, porque no solo favorece el reclutamiento y la regeneración de nuevos operativos, sino que además atrae para la atención de terceras partes que pueden ser sugestionadas para buscar una salida al conflicto al que se apela para recurrir a la violencia (Merlos, 2008, p. 80). La grabación de la cinta de video o audio, o el documento escrito que todo terrorista debe legar a la prosperidad con una finalidad propagandística, constituye igualmente, un "punto de no retorno" puesto que la vergüenza que para todo aspirante podría suponer el arrepentirse una vez grabado el mensaje de despedida es inadmisible. Al mismo tiempo este testimonio sirve para despedirse de su familia y amigos y alentar a la lucha y a futuros candidatos a hombre bomba. En todo caso, en estos testamentos se pueden extraer algunos símbolos y significados que reflejan cualidades personales del mártir suicida, el motivo que existe detrás de la operación, el objetivo y otros símbolos y signos. Tal es así, que en uno de los primeros videos difundidos de una mujer suicida, Sanaa Muhaidly, explicaba que los motivos que le había llevado a protagonizar un acto suicida era la necesidad de liberar a su comunidad de la ocupación extranjera (Jaber, 1997). Y todo porque los que deciden convertirse en un atacante suicida se ve a sí mismo como mártires que están cumpliendo con un mandato divino para proteger su religión frente al atacante infiel (Ganor, 2007, p. 10). Además, como algunos de estos hombres bomba provienen de un bajo nivel social, con su muerte 
contribuye a mejorar la situación socioeconómica de sus familias, ya que estas reciben honores y una recompensa económica por parte de organizaciones de caridad, o el propio grupo terroristas, o la sociedad de su entorno. Por no mencionar los beneficios personales que perciben, al ganar la vida eterna en el Paraíso para él y para 70 familiares.

Estos videos sirven como elementos propagandísticos, no solo consiguen un efecto a nivel internacional sino nacional. En este sentido, el principal objetivo es provocar miedo e indefensión a la sociedad internacional y arrancar el apoyo de la población autóctona. Esto último es esencial para evitar la detección y la eliminación del grupo por parte de las fuerzas de seguridad de la sociedad adversaria. Sin la colaboración amplia de la población local, los grupos terroristas suicidas serían esencialmente vulnerables a la penetración de intrusos, a la deserción y a los informantes (Pape, 2006, p. 104). De ahí, que sea necesario tener la suficiente popularidad como para que la sociedad en su conjunto esté dispuesta a silenciar a los potenciales informantes (Pape, 2006, p. 104). Además, ese apoyo es esencial para el martirio. A ser posible, los grupos terroristas necesitan que los terroristas suicidas sean aceptados como mártires en la comunidad. Es un aspecto importante, porque la probabilidad de que se presenten nuevos voluntarios es mayor si se espera obtener un estatus importante después de la muerte (Pape, 2006, p. 104). Es más, si la comunidad rehúsa asignar la calificación de mártires a los terroristas suicidas, existe el riesgo de que sus actos sean condenados como socialmente inaceptables (Pape, 2006, p. 105).

Pero además de la realización del video, el candidato lleva a cabo, un día antes del ataque, un ritual de purificación, se coloca sus ropas limpias y trata de escuchar alguna de las plegarias comunes en la Mezquita. Al mismo tiempo, él se dedica a recitar la oración tradicional de los musulmanes antes de la batalla, y le pide a Alá que le perdone sus pecados y bendiga en su misión. Luego, pone el Corán junto a su pecho, sobre el corazón y se coloca una cinta de explosivos en la cintura, si ese es el caso. Más tarde, el jefe, le da su adiós y lo despide con las siguientes palabras: "Pueda Alá estar contigo, puede Alá darte el triunfo para que logres el Paraíso". El futuro mártir entonces responde: "Quiera Dios, que nos encontremos en el Paraíso". 
Respecto a la organización del funeral, mencionar que el mismo incluye el entoldado de su casa, en la que los vecinos toman café y ofrecen sus condolencias a los familiares de los mártires. Incluso algunos grupos abonan una mensualidad, guiados por los dichos de Mahoma, de que aquél que

Ayuda a un combatiente es como uno de ellos. El que ayuda a la familia de un combatiente es como si él mismo hubiera luchado, y financia la atención sanitaria y la educación de sus hijos. Hombres y mujeres saben que el mártir no huye de la vida. Está construyendo el futuro de sus hijos (declaraciones al Times de Musa Abu Marzuk, número dos de Hamás, residente en Damasco, abril de 2002).

Además como se ha mencionado anteriormente, el organizador deberá encargase de la distribución del video que muestra las últimas palabras del "mártir.

\subsection{La repercusión de los atentados "suicidas" y las ventajas de este tipo de tácticas}

Según datos de la Rand Corporation, "los ataques suicidas matan en promedio el cuádruple de personas que otros actos terroristas" (Hoffman 2006, p. 42). Si las organizaciones terroristas optan por estrategias suicidas principalmente es porque infringen daños superiores, obtienen mayor atención mediática, contribuyen al logro de objetivos (Enkerlin y Zatarain, 2011, p. 151) y resultan extraordinariamente baratos. No obstante, un terrorista suicida se convierte en una especie de "bomba inteligente" que está capacitada para acceder al blanco y elegir el momento y el lugar adecuados para ejecutar el atentado. Así, por ejemplo, un hombre-bomba capaz de detonar dos kilos de explosivos en el interior de un autobús, da como resultado el mismo número de víctimas que treinta kilos de explosivo abandonado en las instalaciones de un centro comercial. Esto, puede convertir a un miembro de la más paupérrima organización terrorista en la más sofisticada "bomba" inteligente, capaz de alcanzar cualquier blanco, y realizar adaptaciones de última hora en función de las medidas de seguridad adoptadas y los imprevistos a los que toda acción terrorista debe enfrentarse. 
Esto hace que las campañas suicidas sea una opción muy atractiva para los competidores más débiles que participan en los conflictos asimétricos (De la Corte y Giménez-Salinas, 2009, p. 12). Más cuando, los grupos terroristas o insurgentes recurren a este tipo de acciones para intentar conseguir la expulsión de las fuerzas de ocupación extranjera, la obtención de la independencia nacional, la desestabilización o el remplazo de un sistema político, la intensificación de un conflicto violento en curso, y la interrupción de un proceso de solución pacífica de los conflictos políticos, étnicos o religiosos (De la Corte y Giménez-Salinas, 2009, p. 11). Por tanto, resulta ser una acción socorrida pero no se da constantemente, porque si no podría perder parte de su efecto. Dada cuenta, que los grupos terroristas o insurgentes podrían encontrar grandes dificultades para reemplazar a sus mártires, y al mismo tiempo, que debilitarían la propia fuerza del grupo, al carecer de efectivos. De ahí, que normalmente las acciones suicidas sean más probables cuando se da uno de estos tres factores: 1) Sensación de estancamiento, ya que las operaciones de suicido pueden ser percibidas como un método eficaz para acelerar la resolución de determinados conflictos. 2) La coexistencia de varios grupos de insurgentes que persiguen objetivos equivalentes: uno de esos grupos pueden utilizar ataques suicidas para capitalizar la atención en su comunidad de referencia. y 3) Preexistencia de la actividad suicida: la adopción de métodos de suicidio por un grupo insurgente puede alentar a otros grupos para introducir este método en su repertorio operativo. Este efecto puede ser reproducido por dos tipos de insurgentes o terroristas: los que están involucrados en el conflicto mismo y los que participan en diferentes enfrentamientos a distancia (De la Corte y Giménez-Salinas, 2009, p. 13).

No obstante, habría que señalar que los atentados suicidas todavía no han conseguido sus objetivos. Aunque es cierto, que han alcanzado alguno, como ha podido ser la retirada de Israel de una zona importante, Gaza y la franja occidental, de manera temporal y parcial entre 1994 y 1995. Pero, en todo caso, resulta sumamente difícil que el mártir pueda conseguir que un Estado adversario renuncie a sus objetivos esenciales para su seguridad y prosperidad. Tal es así, que por ejemplo, el Gobierno de Sri Lanka mantuvo negociaciones, aparentemente serias, con el LTTE entre 
noviembre de 1994 y abril de 1995, pero no cedió en la principal reivindicación de los tamiles, la independencia (Pape, 2006, p. 98).

En cualquier caso, las acciones suicidas proporcionan ciertas ventajas a los grupos terroristas e insurgentes:

- En un atentado suicida el terrorista que desea morir tiene más probabilidades de cumplir su misión y causar mayores daños. Y todo porque los terroristas suicidas pueden ocultar las armas en el cuerpo y hacer ajustes de última hora con más facilidad que los terroristas comunes; también porque tienen mayor capacidad de infiltrarse en los objetivos provistos de una fuerte vigilancia, porque no requieren planes de huida ni equipos de rescate; porque son un modo muy convincente de enviar a la sociedad rival el mensaje de que es posible provocar mayor dolor en el futuro, porque el alto coste que conlleva el propio suicidio indica que no hay represalia capaz de disuadir a los atacantes; porque contribuye a intensificar la credibilidad de futuros atentados, porque indica que nada puede disuadir a los atacantes (Pape, 2006, pp. 44-45), porque se hace estallar el artefacto sobre el blanco, ya que este es invisible para la víctima hasta que hace explotar la bomba. Eso último ayuda a superar la ventaja original del ataque standoff occidental, basado en la selección de blancos a distancia física; porque se pueden atacar los blancos más duros; porque el artefacto no tiene ninguna vulnerabilidad, no se le puede hallar ni mudar ni neutralizar antes de la detonación.

- La participación de mujeres en este tipo de acciones reporta enormes beneficios para los grupos que los emplean, ya que pueden tener acceso a objetivos mucho más rentables. Dado que las mujeres tienen, generalmente, mayor facilidad para tener acceso a sitios prohibidos o limitados a los hombres, tanto por su propia condición femenina como por las tareas propias tradicionales (hospitales, personal de limpieza, empleadas del hogar, intérpretes, camareras, etc.) (Baños, 2008, p. 15). Además, para una mujer, como indica Fighel (2003), es más fácil mezclarse entre los viandantes, pudiendo adoptar una apariencia completamente 
occidental -como en el peinado o llevando minifaldas-, lo que hará que no levante ninguna sospecha.

- Los ataques suicidas atraen a una amplia cobertura mediática, como resultado del gran número de bajas. Un ataque suicida es un acontecimiento de interés periodístico de los medios de comunicación, ya que indica una pantalla de gran determinación y la inclinación para el auto-sacrificio por parte de los terroristas (Ganor, 2007).

- El terrorismo moderno es una guerra psicológica y los ataques suicidas intensifican este efecto psicológico. El número de víctimas, el autor y la cobertura mediática de los ataques hace hincapié en el sentimiento de miedo y ansiedad en la población destinataria. Por la naturaleza aleatoria del ataque y la incapacidad para identificar y detener al atacante se extiende un sentimiento de impotencia, que caracteriza a este tipo especial de ataque en comparación con el modus operandi de los terroristas de otros (Ganor, 2007).

- El ataque suicida es normalmente tecnología muy primitiva. Es barato y fácil de comprar los explosivos necesarios para el ataque y de preparar el IED (dispositivo explosivo improvisado). El artefacto explosivo es un conocimiento muy simple y básico de la preparación de un circuito eléctrico con una batería y un botón "dentro y fuera", es todo lo que se necesita. Por lo tanto, el punto de vista técnico no es un factor limitante de este fenómeno $(\mathrm{Ga}-$ nor, 2007).

- Los ataques suicidas generan mártires, ya que a medida que se suicidan, ganan en prestigio ante los ojos de la sociedad, y por tanto, no les resulta difícil reclutar a nuevos candidatos suicidas.

\subsection{Contramedidas para evitar en lo posible las operaciones "suicidas"}

Las medidas antiterroristas que están adoptando los gobiernos para combatir el terrorismo pueden clasificarse como ofensiva y defensivas. 
Pero hay que hacer una pequeña observación, ya que las medidas para combatir el terrorismo suicida son diferentes a las que hay que tomar para frenar al terrorismo general. Por ejemplo, la fuerza militar puede resultar inapropiada para la acción suicida. De ahí, que muchos Estados se encuentren en la urgente necesidad de explorar nuevos métodos para frustrar estos ataques, lo que limita sus efectos y la búsqueda de nuevas tecnologías y regulaciones que ayudarán a reducir el alcance de este fenómeno (Ganor, 2007).

En todo caso, las medidas ofensivas consistentes en ataques anticipados contra las organizaciones o sus líderes. Por ejemplo, si se realizan ataques preventivos se puede reducir sus recursos y capacidades, es decir, la destrucción de su infraestructura de formación, la captura de sus dirigentes y militantes, o la ruptura de sus fuentes de financiación (De la Gorte y Giménez-Salinas, 2009, p. 16). Aunque como señala Bloom (2005a) esto también podría contribuir a aumentar el número de simpatizantes dispuestos a sustituir a los insurgentes que han sido arrestados o asesinados. Otra medida en este sentido sería la recopilación de información sobre las organizaciones radicales, ya que de esta manera se podría llegar a conocer las intenciones de los grupos radicales, sus planes, sus recursos, sus procedimientos, etc. (De la Corte y Giménez-Salinas, 2009, p. 17). Otra sería aplacar cualquier condición política, cultural o socio-económica que pudiera promover el sentido de amenaza o sentimiento de humillación, de venganza o de odio dentro de colectivos virtuales que pudieran apoyar los terroristas suicidas y su organización insurgente (Kronin, 2003). Otra sería el "appling" que es una media operativa que intenta impedir el acceso a la propaganda distribuida para difundir la cultura del martirio entre los ciudadanos (De la Corte y Giménez-Salinas, 2009: 17). Y otra sería la implementación de actividades de información y contrapropaganda para contrarrestar los argumentos e ideas para la violencia legítima del suicidio (De la Corte y Giménez-Salinas, 2009, p. 17).

Las medidas defensivas son las que consisten en intentar evitar que los atacantes suicidas alcancen sus objetivos. Para ello, se establecen medidas físicas, las orientadas a frustrar la preparación de ataques, y las destinadas a detener a grupos o individuos que inician ataques suicidas. Las primeras consisten en una serie de barreras, que incluyen vallas en 
la frontera, un sistema de barricadas y puestos de control, guardias a la entrada de los lugares públicos, cámaras y sistema de vigilancia en las instalaciones. Por ejemplo, las barreras alrededor de la Franja de Gaza, que fueron colocadas al comienzo de la Segunda Intifada, lograron disminuir en un 18\% los ataques suicidas provenientes de esta región. Las segundas, se basan en las acciones que llevan a cabo las distintas agencias de inteligencia y la buena coordinación de estas, además de la habilidad para actuar prontamente contra el enemigo. Por ejemplo, se dice que, durante la Segunda Intifada, las Fuerzas de Defensa de Israel abortaron unos 406 ataques suicidas de los 541 que se intentaron, y todo ello, gracias a que las fuerzas de seguridad realizaron incursiones contra los escondites de los terroristas. La tercera, han ido dirigidas a intentar detener los ataques. Para ello, se ha tratado de imponer un costo a las familias, como por ejemplo demoler el hogar de los terroristas suicidas, ya que consideran que aunque una persona esté dispuesta a morir, no querrá ver sufrir a su familia; se ha tratado de infligir un duro castigo al grupo que comete los ataques, especialmente lanzando operativos contra los líderes de esos grupos, ya que se supone que el grupo no deseará que la organización fuese extremadamente perjudicada; y se ha tratado de castigar a la población de donde provienen los atacantes suicidas, ya que se estima que el análisis coste y beneficio podría generar una opinión pública contraria a los ataques suicidas.

El problema es que este tipo de medidas han tenido un éxito muy relativo, por ejemplo, con esta última la población palestina considera que el Gobierno de Israel no les ofrece ninguna alternativa ni compensación, por lo cual no tiene nada que perder, y siguen apoyando a los terroristas suicidas. En este sentido, lo lógico es que se apliquen medidas efectivas para la implantación de políticas de ayuda social a nivel local, es decir, las acciones deben encaminarse a cubrir todo tipo de carencias y necesidades, pero eso sí antes de que lo hagan los grupos terroristas e insurgentes. De esta manera, conseguirán un triple resultado favorable: por un lado, el inherente a la propia ayuda que cubre a estas necesidades; por otro, la limitación del campo de actuación de estas organizaciones de cara a conseguir apoyo y militante; y en último lugar, ese apoyo en concepto de agradecimiento se trasvasaría de estas organizaciones terroristas al Estado mismo (Martínez, 2010, p. 35). 
